\title{
Low activity of complement in the cerebrospinal fluid of the patients with various prion diseases
}

\author{
Cao Chen ${ }^{1,2+}$, Yan Lv ${ }^{1,2+}$, Qi Shi ${ }^{1,2}$, Wei Zhou ${ }^{1,2}$, Kang Xiao ${ }^{1,2}$, Jing Sun ${ }^{1,2}$, Xiao-Dong Yang ${ }^{1,2}$ \\ and Xiao-Ping Dong ${ }^{1,2,3^{*}}$
}

\begin{abstract}
Background: The aim of this study was to analyze the state of activity and levels of complement in the cerebrospinal fluid (CSF) of patients with various prion diseases (PrDs).

Findings: The proteomic data emphasized the levels of 20 known complement components found in the CSF of the SCJD panel that were lower than those found in the non-PrD panel. $50 \%$ of the complement hemolytic activity (CH50) assays revealed significantly lower activity of complement in the CSF of the SCJD panel. The decreased levels of three key complement subunits, $C 3 a / a, C 4 \beta$, and C9 in the CSF of the sCJD panel were verified by Western blots. Furthermore, the CH50 values in the CSF of $136 \mathrm{sCJD}, 39 \mathrm{gCJD}, 22 \mathrm{FFI}$ and 145 non-CJD patients were individually tested. Compared with the control of non-PrD, the CH50 value in the CSF specimens of various PrDs, especially in three subtypes of inherited PrDs, were significantly lower. Relationship analysis identified that the CH50 activity in the CSF was negatively associated with the protein 14-3-3 positive in the CSF.
\end{abstract}

Conclusion: These results indicate a silent complement system in the CSF of PrD patients.

Keywords: Prion diseases, CSF, Complement component, CH50, sCJD

\section{Multilingual abstracts}

Please see Additional file 1 for translations of the abstract into the six official working languages of the United Nations.

\section{Background}

Human prion diseases (PrDs) are a category of fatal neurodegenerative disorders including Creutzfeldt-Jakob disease (CJD), Gerstmann-Sträussler-Scheinker syndrome (GSS), fatal familial insomnia (FFI) and Kuru [1]. Surrogate biomarkers in CSF are screened for alterations, which not only identify the diagnostic markers for CJD, but also provide insight for understanding the pathogenesis. So far, only the

\footnotetext{
*Correspondence: dongxp238@sina.com

${ }^{\dagger}$ Equal contributors

'State Key Laboratory for Infectious Disease Prevention and Control, National Institute for Viral Disease Control and Prevention, Chinese Center for Disease Control and Prevention, Chang-Bai Rd 155, Beijing 102206, China

${ }^{2}$ Collaborative Innovation Center for Diagnosis and Treatment of Infectious

Diseases, Zhejiang University, Hangzhou 310003, China

Full list of author information is available at the end of the article
}

immunoblot for the 14-3-3 protein in CSF is included in the diagnostic criteria for sporadic CJD (sCJD) [2].

The complement system, which consists of at least 30 kinds of soluble and membrane-bound proteins, is an immune-defense mechanism with a wide range of effects that take place in the central nervous system (CNS). Evidence suggests that the activation of complement components occurs in patients with various neurodegenerative disorders [3-6], and that certain complement proteins are deregulated during prion infection [5, 7-12]. Our previous proteomic study has revealed that some complement components were lower in the CSF of sCJD patients [13]. However, the exact relationship has yet to be proven.

\section{Methods}

This study was approved by the Ethical Committee of the National Institute for Viral Disease Control and Prevention, China CDC, under protocol 2009ZX10004-101.

To verify the changes of complement in the CSF of sCJD patients according to the proteomic code, we 
Table 1 The relevant characteristics of the patients with non-CJD and SCJD, gCJD and FFI

\begin{tabular}{|c|c|c|c|c|c|}
\hline \multirow[t]{2}{*}{ Clinical features } & \multirow[t]{2}{*}{ non-CJD } & \multirow[t]{2}{*}{ SCJD } & \multicolumn{2}{|l|}{ gCJD } & \multirow[t]{2}{*}{$\mathrm{FFI}$} \\
\hline & & & $\mathrm{T} 188 \mathrm{~K}$ & E200K & \\
\hline Number (n) & 145 & 136 & 25 & 14 & 22 \\
\hline Gender (M/F) & $71 / 74$ & $72 / 64$ & $16 / 9$ & $7 / 7$ & $9 / 13$ \\
\hline Median age at onset (range) (y) & $61(45-89)$ & $65(47-81)$ & $50(40-85)$ & $56(44-68)$ & $47.5(19-63)^{a}$ \\
\hline Age at onset $<50$ years (\%) & $7(4.8)$ & $3(2.2)$ & $2(8)$ & $4(28.6)$ & $12(54.5)$ \\
\hline Age at onset $50-70$ years (\%) & $114(78.6)$ & $96(70.6)$ & $17(68)$ & $10(71.4)$ & $10(45.5)$ \\
\hline Age at onset $>70$ years (\%) & $24(16.6)$ & $37(27.2)$ & $6(24)$ & $0(0)$ & $0(0)$ \\
\hline Patients with PRNP gene sequenced (\%) & $145(100)$ & $136(100)$ & $25(100)$ & $14(100)$ & $22(100)$ \\
\hline \multicolumn{6}{|l|}{ Codon 129 genotype } \\
\hline Met-Met/Total (\%) & $143 / 145(98.6)$ & 133/136 (97.8) & $13 / 25(100)$ & $14 / 14(100)$ & $22 / 22(100)$ \\
\hline Met-Val/Total (\%) & $2 / 145(1.4)$ & $3 / 136(2.2)$ & $0 / 25(0)$ & 0/14 (0) & $0 / 22(0)$ \\
\hline Val-Val/Total (\%) & $0 / 145(0)$ & $0 / 136(0)$ & $0 / 25(0)$ & $0 / 14(0)$ & $0 / 22(0)$ \\
\hline EEG Typical/Total (\%) & $9 / 145(6.2)$ & $92 / 136(67.6)^{b}$ & $3 / 25(12)$ & $8 / 14(57.1)^{b}$ & $0 / 22(0)$ \\
\hline 14-3-3 Positive/Total (\%) & $29 / 145(20)$ & $99 / 136(72.8)^{b}$ & $18 / 25(72)^{b}$ & $14 / 14(100)^{b}$ & $6 / 22(27.2)$ \\
\hline Progressive dementia/Total (\%) & $121 / 145(83.4)$ & $128 / 136(94.1)^{b}$ & $20 / 25(80)$ & $13 / 14(92.9)$ & $17 / 22(77.3)$ \\
\hline Myoclonus (\%) & $33 / 145(22.8)$ & $106 / 136(77.9)^{b}$ & $15 / 25(60)^{b}$ & $10 / 14(71.4)^{b}$ & $12 / 22(54.5)^{b}$ \\
\hline Visual or cerebellar disturbance (\%) & $22 / 145(15.2)$ & $88 / 136(64.7)^{b}$ & $18 / 25(72)^{b}$ & $11 / 14(78.6)^{b}$ & $11 / 22(50)^{b}$ \\
\hline Pyramidal or extramidal dysfunction (\%) & $70 / 145(48.3)$ & $104 / 136(76.5)^{b}$ & $19 / 25(76)^{c}$ & $12 / 14(85.7)^{c}$ & $13 / 22(59.1)$ \\
\hline Akinetic mutism (\%) & 24/145 (16.6) & $66 / 136(48.5)^{b}$ & $10 / 25(40)^{c}$ & $8 / 14(57.1)^{b}$ & $3 / 22(13.6)$ \\
\hline
\end{tabular}

a compared with non-PrD controls by Mann-Whitney $U$ test and the superscript of "a" means $P<0.01$

$\mathrm{b} / \mathrm{c}$ compared with non-PrD controls through Chi-Square test and the superscript of " $\mathrm{b}$ " represents $\mathrm{p}<0.01$ and that of "c" indicates $P<0.05$

reviewed 37 CSF samples from probable sCJD patients who tested positive for $14-3-3$ protein in their CSF and typical periodical sharp-wave complexes (PSWC) in their EEG. We also analyzed 36 CSF samples from non-CJD patients, who were CSF 14-3-3 negative and had normal levels of EEG. These samples were taken from the CSF bank in the China CJD Surveillance Center (Additional file 2: Table S1). $50 \mu \mathrm{l} \mathrm{CSF} \mathrm{samples} \mathrm{were} \mathrm{taken} \mathrm{from} \mathrm{each}$ group and labeled sCJD or non-CJD, respectively. Furthermore, the CSF samples were further subdivided as such: 136 sCJD, 39 genetic CJD (gCJD), 22 FFI and 145 nonCJD (Table 1). This allowed us to screen the complement

Table 2 Comparison of the complement proteins in CSF between the groups of probable SCJD and non-CJD in proteomic assay [11]

\begin{tabular}{|c|c|c|c|c|c|}
\hline No. & Complement components & UniProt accession & MW (KDa) & Fold of change & $P$-value \\
\hline 1 & Complement C4-B & P0C0L5 & 193 & 0.67 & $5.62 \mathrm{E}-04$ \\
\hline 2 & Complement component $\mathrm{C} 7$ & P10643 & 94 & 0.55 & $5.84 \mathrm{E}-04$ \\
\hline 3 & Complement $\mathrm{C} 2$ & P06681 & 83 & 0.53 & $3.72 \mathrm{E}-03$ \\
\hline 4 & Complement component C9 & P02748 & 63 & 0.5 & $1.07 \mathrm{E}-07$ \\
\hline 5 & Complement factor B & P00751 & 86 & 0.34 & $1.78 \mathrm{E}-04$ \\
\hline 6 & Complement $\mathrm{C}$ 1s subcomponent & P09871 & 77 & 0.83 & $5.39 \mathrm{E}-03$ \\
\hline 7 & Complement $\mathrm{C} 1 \mathrm{q}$ subcomponent subunit $\mathrm{C}$ & P02747 & 26 & 0.71 & $6.24 \mathrm{E}-03$ \\
\hline 8 & Complement component C6 & P13671 & 105 & 0.70 & $5.84 \mathrm{E}-03$ \\
\hline 9 & Complement factor H-related protein 1 & Q03591 & 38 & 0.70 & $6.53 \mathrm{E}-03$ \\
\hline 10 & Complement C5 & P01031 & 188 & 0.67 & $5.62 \mathrm{E}-04$ \\
\hline 11 & Complement $\mathrm{C} 1 \mathrm{r}$ subcomponent-like protein & Q9NZP8 & 53 & 0.63 & $1.18 \mathrm{E}-03$ \\
\hline 12 & Complement component $\mathrm{C} 8$ beta chain & P07358 & 67 & 0.58 & 8.73E-04 \\
\hline 13 & Complement factor $\mathrm{H}$ & P08603 & 139 & 0.55 & $7.78 \mathrm{E}-04$ \\
\hline 14 & Complement factor I & P05156 & 66 & 0.55 & $5.84 \mathrm{E}-04$ \\
\hline 15 & Complement $\mathrm{C} 1 \mathrm{q}$ subcomponent subunit B & $\mathrm{P} 02746$ & 27 & 0.53 & 5.77E-04 \\
\hline 16 & Complement $\mathrm{C} 3$ & P01024 & 187 & 0.13 & 4.43E- 05 \\
\hline 17 & Complement decay-accelerating factor & P08174 & 41 & 0.90 & 4.35E-01 \\
\hline 18 & Complement $\mathrm{C} 1 \mathrm{r}$ subcomponent & P00736 & 80 & 0.88 & $1.13 \mathrm{E}-01$ \\
\hline 19 & Complement component $\mathrm{C} 8$ gamma chain & P07360 & 22 & 0.79 & $2.79 \mathrm{E}-01$ \\
\hline 20 & Complement component $\mathrm{C} 8$ alpha chain & P07357 & 65 & 0.73 & $1.16 \mathrm{E}-01$ \\
\hline
\end{tabular}




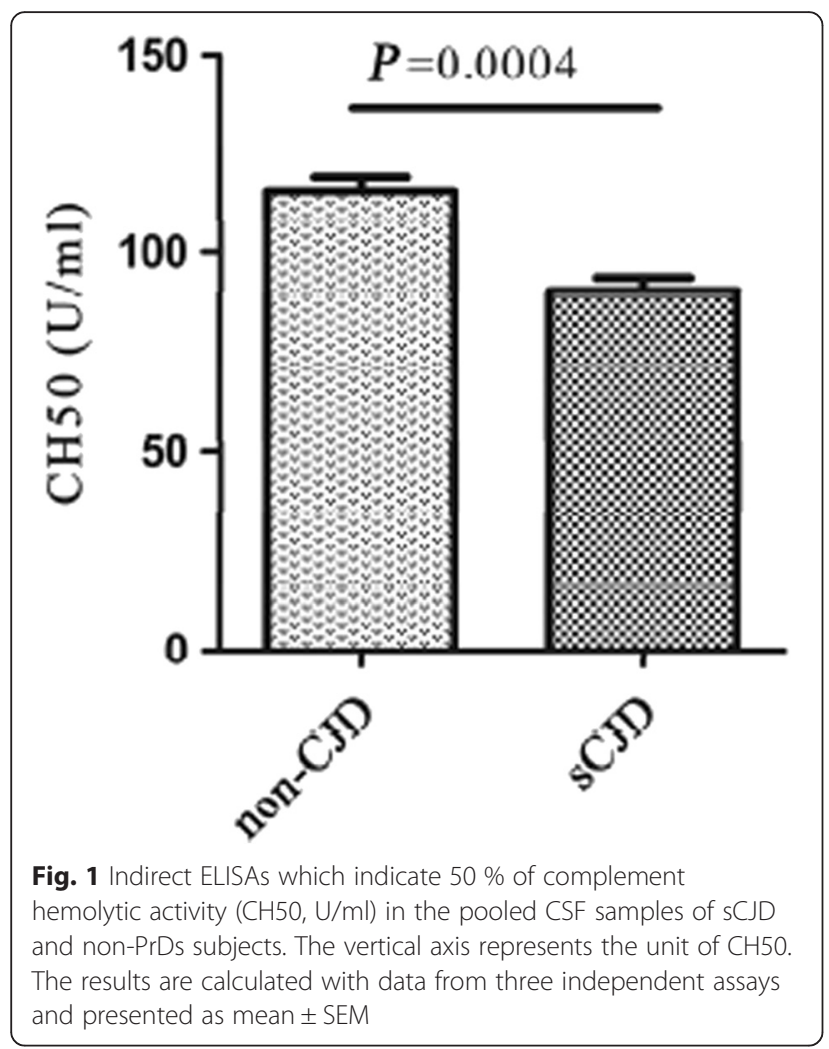

activity individually. The possible clinical diagnoses of those 145 non-CJD cases were summarized in Additional file 3: Table S2.

All enrolled CSF samples were obtained by standard clinical procedures and were free of blood contamination. Routine CSF biochemistry assays of those specimens, including cell count, glucose, and total protein were all within the normal ranges.

The detection of the $50 \%$ of complement hemolytic activity $(\mathrm{CH} 50, \mathrm{U} / \mathrm{ml})$ in CSF $(50 \mu \mathrm{l}$ of each tested sample) was derived from the commercial double-antibody sandwich enzyme-linked immunosorbent assays (ELISAs, YAD, China). Western blots for the complement components $\mathrm{C} 3 \mathrm{a} / \alpha, \mathrm{C} 4 \beta$ and C9 in the panels of the pooled CSF $(20 \mu \mathrm{l}$ of each tested sample) were conducted using anti-C3a/ $\alpha$ mAbs (sc-47688), anti-C4 $\beta$ pAbs (sc-25816) and anti-C9 mAbs (sc-390000) (Santa Cruz biotechnology Inc). The detailed procedures of CH50 ELISA and Western blot are described elsewhere [5]. The data was processed with GraphPad Prism 5 and SAS 9.2 statistics software.

\section{Findings}

Based on the raw data of our previous study [13], we identified 20 complement-related components that were differentially expressed in the SCJD group (Table 2). All those identified complement components in the CSF of the sCJD group were down-regulated compared with

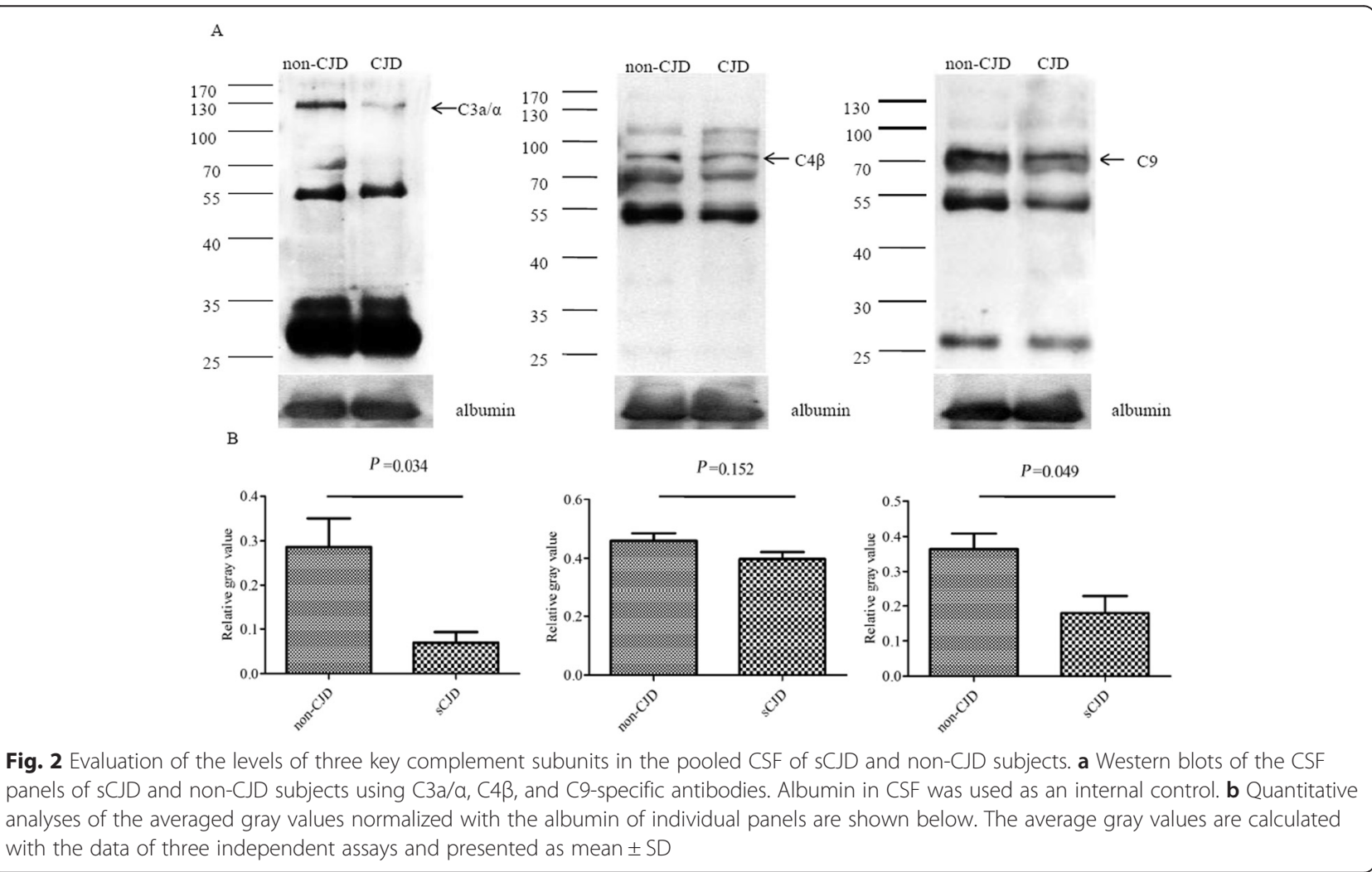




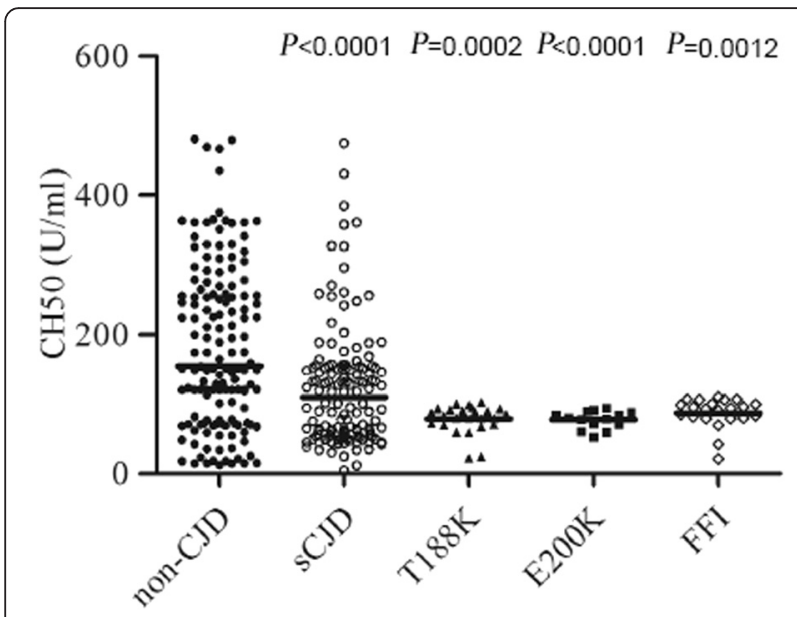

Fig. 3 Detection of individual CSF levels of the total complement activity among a sampling of human prion diseases using indirect ELISAs which indicate $50 \%$ of complement hemolytic activity. The solid line within each group represents the median of $\mathrm{CH} 50$ values. The $P$ values between the groups of non-CJD subjects and individual prion diseases are labeled above

those of non-CJD group, among which were 16 proteins that showed significant statistical difference $(P<0.01) .5$ out of 20 complement components were statistically different at the $95 \%$ confidence interval (gray box in Table 2) by the Peptide Prophet algorithm [14], including C4-B, C7, C2, C9 and factor B.

To obtain more evidence for the alteration of complement activity and complement components in the CSF of sCJD patients, CH50 in the CSF panels of sCJD and nonCJD (protein concentration: $283 \pm 15 \mathrm{mg} / \mathrm{l}$ for the sCJD panel and $315 \pm 23 \mathrm{mg} / \mathrm{l}$ for the non-CJD panel) were analyzed using a commercial indirect ELISA kit. Compared with the panel of non-CJD, CH50 in the sCJD panel was significantly lower (Fig. 1, $P<0.001$ ). Furthermore, the decreased levels of three key subunits of complement $\mathrm{C} 3 \mathrm{a} / \alpha$, C4 $\beta$, and C9 in complement cascades in the CSF panel of sCJD were observed by Western blots (Fig. 2).

To evaluate CH50 activity in the CSF of PrD patients, CSF samples from 197 cases of various PrDs and 145 CSF samples from non-PrDs were given CH50 assays separately. As shown in Fig. 3, the median CSF CH50 values in the group of sCJD, T188K-gCJD, E200K-gCJD, and FFI were significantly lower than that of non-CJDs. Further analysis showed that the $\mathrm{CH} 50$ values in $49.3 \%$ $(67 / 136)$ of sCJDs, $92.0 \%(23 / 25)$ of T188K gCJDs, $100 \%$ (14/14) E200K gCJDs, and $77.3 \%$ (17/22) of FFI were below $100 \mathrm{U} / \mathrm{ml}$, whereas only $28.3 \%$ (41/145) of non-CJD were in this zone (Table 3). This data indicates a profile of lower $\mathrm{CH} 50$ values in the CSF of $\mathrm{PrD}$ patients. Unlike the wide distribution of $\mathrm{CH} 50$ in samples taken from SCJD and non-CJD groups, the distribution of CSF CH50 values in T188K-, E200K-gCJD, and FFI were much narrower. Additionally, the CSF $\mathrm{CH} 50$ values do not correspond with the intervals from the aforementioned diseases onset to sampling in all tested groups (Additional file 4: Table S3). Nor do they influence the survival time of the $31 \mathrm{sCJD}$ patients (Additional file 5 : Figure S1).

To address the potential factor(s) correlated with the CSF CH50 activity, some clinical and laboratory parameters from the enrolled patients were statistically analyzed. Univariate analysis illustrated a significant correlation between 14-3-3 and CH50 (Table 4, $P=0.003$ ). Further multivariate logistic regression proposed that only the presence of 14 3-3 in CSF showed the notable correlation with CSF CH50 activity $(P=0.004)$. To further evaluate the relationship between CH50 activity and 14-3-3 positive CSF, all enrolled cases were grouped depending if they were $14-3-3$ positive or negative. As shown in Fig. 4, in the context of 342 tested samples, the CSF $\mathrm{CH} 50$ values of the cases that were $14-3-3$ positive (median: $86.03 \mathrm{U} / \mathrm{ml}$ ) were clearly lower than those that were 14-3-3 negative (median: $143.6 \mathrm{U} / \mathrm{ml})(P<0.0001)$. Subsequent assays based on various diagnoses illustrated lower CSF CH50 activity in the sCJD cases that were $14-3-3$ positive $(P<0.0001)$. NonCJD cases that tested 14-3-3 positive, in contrast, tested relatively higher without statistical difference $(P=0.545)$ (Fig. 4). Lower $\mathrm{CH} 50$ values were also detected in the cases of genetic PrDs that were 14-3-3 positive, but those values were only significant in the gCJD group $(P=0.0387)$. This demonstrates a negative correlation of lower CSF levels and CH50 activity with 14-3-3 positive PrD patients.

This study has been the first time that lower CSF complements in $\operatorname{PrD}$ patients have been observed. The

Table 3 The numbers of CSF samples among different human prion diseases according to various $\mathrm{CH} 50$ value ranges

\begin{tabular}{|c|c|c|c|c|c|c|}
\hline \multirow[t]{2}{*}{ Groups } & \multirow{2}{*}{$\begin{array}{l}\text { CH50 (U/ml) } \\
\text { Median (min, max) }\end{array}$} & \multirow[t]{2}{*}{$P$-value ${ }^{a}$} & \multicolumn{4}{|c|}{ CH50 (U/ml) \% (case No./group No.) } \\
\hline & & & $<100$ & $100-200$ & $200-300$ & $>300$ \\
\hline non-CJD & $154.066(12.407-480.312)$ & - & $28.3 \%(41 / 145)$ & $29.7 \%(43 / 145)$ & $24.1 \%(35 / 145)$ & $17.9 \%(26 / 145)$ \\
\hline sCJD & $108.55(4.56-474.40)$ & $<0.0001$ & $49.3 \%(67 / 136)$ & $38.2 \%(52 / 136)$ & $7.4 \%(10 / 136)$ & $5.1 \%(7 / 136)$ \\
\hline T188K & $88.432(22.39-109.237)$ & 0.0002 & $92 \%(23 / 25)$ & $8 \%(2 / 25)$ & 0 & 0 \\
\hline E200K & $76.577(52.03-94.03)$ & $<0.0001$ & $100 \%(14 / 14)$ & 0 & 0 & 0 \\
\hline $\mathrm{FFI}$ & $92.905(21.43-109.70)$ & 0.0012 & $77.3 \%(17 / 22)$ & $22.7 \%(5 / 22)$ & 0 & 0 \\
\hline
\end{tabular}

${ }^{\mathrm{a}}$ Mann-Whitney $U$ test 
Table 4 Multivarivate logistic regression of the levels of CSF CH50 and relational influence factors

\begin{tabular}{|c|c|c|c|}
\hline & Factors & OR $95 \%(C l)$ & $P$-value \\
\hline \multirow[t]{32}{*}{ Univariate analysis } & Gender & & \\
\hline & Male & $0.793(0.456,1.376)$ & 0.409 \\
\hline & Female & Reference & - \\
\hline & Age of onset & & \\
\hline & $<50$ & $1.260(0.343,4.623)$ & 0.728 \\
\hline & $50-70$ & $1.503(0.713,3.169)$ & 0.285 \\
\hline & $>70$ & Reference & \\
\hline & Codon 129 genotype & & \\
\hline & Met-Met & $1.114(0.107,11.648)$ & 0.928 \\
\hline & Met-Val & Reference & \\
\hline & EEG & & \\
\hline & n.d. & $0.231(0.127,1.003)$ & 0.272 \\
\hline & Positive & $0.684(0.348,1.346)$ & \\
\hline & Negative & Reference & \\
\hline & $14-3-3$ & & 0.003 \\
\hline & Positive & $0.372(0.195,0.707)$ & \\
\hline & Negative & Reference & \\
\hline & Progressive dementia & & 0.814 \\
\hline & Yes & $1.104(0.485,2.510)$ & \\
\hline & No & Reference & \\
\hline & Myoclonus & & 0.703 \\
\hline & Yes & $1.137(0.588,2.199)$ & \\
\hline & No & Reference & \\
\hline & Visual or cerebellar disturbance & & 0.165 \\
\hline & Yes & $0.639(0.340,1.202)$ & \\
\hline & No & Reference & \\
\hline & Pyramidal or extramidal dysfunction & & 0.090 \\
\hline & Yes & $0.602(0.335,1.082)$ & \\
\hline & No & Reference & \\
\hline & Akinetic mutism & & 0.314 \\
\hline & Yes & $0.692(0.337,1.419)$ & \\
\hline & No & Reference & \\
\hline \multirow[t]{3}{*}{ multivarivate logistic regression } & $14-3-3$ & & 0.004 \\
\hline & Positive & $0.362(0.182,0.722)$ & \\
\hline & Negative & Reference & \\
\hline
\end{tabular}

n.d. represents not detected

changes in complement components in CSF have either decreased [15] or increased [4]. However, the CSF samples in those studies are not from a healthy control group, but from patients with various neurological disorders. Activation of the complement system is frequently detected in the brains of $\operatorname{PrD}$ patients. The reason for this remains unclear, in addition to the relatively silent complement. It might be assumed that the recruitment of the large amount of complement components in the brain $[3,5]$, such as forming $\mathrm{C} 1 \mathrm{q}-\mathrm{PrP}^{\mathrm{Sc}}$ complex $[16,17]$ and membrane attack complex (MAC) [5], might lead to smaller amounts of complement penetrating CSF.

Unlike the wide-range distribution of CSF $\mathrm{CH} 50$ values in SCJD, the $\mathrm{CH} 50$ values in the three subtypes of genetic PrDs are low with a narrow range. It indicates a silent state of the innate immune system in the central 


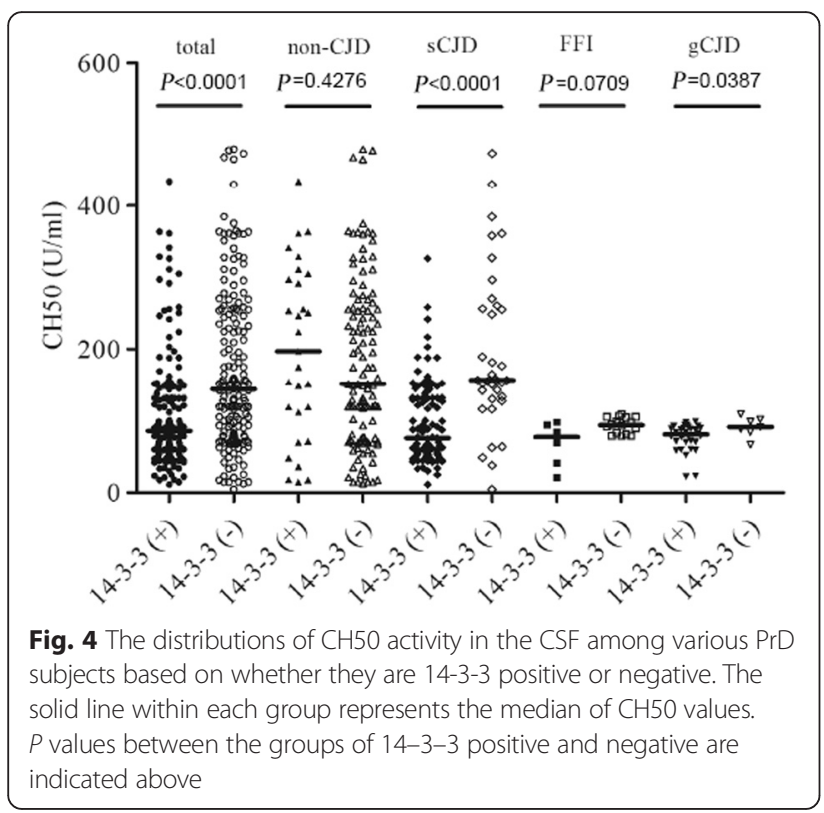

nervous system during the pathogenesis of genetic PrDs. In accordance with our previous study, microglia and some cytokines are silent in the post-mortem brains of FFI and G114V gCJD cases, while some are obviously activated in other types of SCJD cases [18]. Recent iTRAQ-based proteomic study of the brain tissues of sCJD, FFI, and G114V gCJD show multiple pathways involving immunity and infection in the brains of SCJD subjects, except for hereditary cases [19]. Additionally, the diversity of clinical and pathological characteristics in SCJD may also be contributing factors to the variation in $\mathrm{CH} 50$ present within CSF.

14-3-3 positive CSF samples are the unique factor correlated with $\mathrm{CH} 50$ values found in the CSF of sCJD patients. The exact molecular association between these two factors is unknown. Contrary to the well-known diagnostic evidence for sCJD, the correlation of 14-3-3 CSF samples with brain pathology in CJD are rarely reported, and draw controversial conclusions [20-22]. 143-3 samples are also associated with the alterations of other proteins in the CSF of sCJD patients. Our recent publication illustrates that higher levels of tau isoforms containing Exon-2 and Exon-10 segments in sCJD patients with 14-3-3 positive CSF [23]. The NSE level in CSF of sCJD patients is also associated with 14-3-3 positive readings [24]. In that case, one might assume that 14-3-3 positive CSF samples of sCJD patients correlate with the alterations of $\mathrm{CH} 50$ values and other biomarkers in CSF, thus representing a (sCJD) diseaseassociated feature. Nevertheless, the exact molecular mechanism of 14-3-3 positive and lower $\mathrm{CH} 50$ levels in the CSF of sCJD patients deserves further study.

\section{Conclusions}

The complement activities in the CSF of patients with prion diseases (including SCJD, gCJD, and FFI), are lower than their non-CJD counterparts are. Additionally, subjects whose CSF samples tested 14-3-3 positive exhibit lower complement activity in SCJD patients.

\section{Additional files}

Additional file 1: Multilingual abstracts in the sex official working languages of the United Nations. (PDF $237 \mathrm{~kb}$ )

Additional file 2: Table S1. The relevant characteristics of CSF samples between the group of probable sCJD and non-CJD. (DOCX 24 kb)

Additional file 3: Table S2. The clinical diagnoses of 145 non-CJD cases. (DOCX $23 \mathrm{~kb}$ )

Additional file 4: Table S3. Analysis of $\mathrm{CH} 50$ values in CSF from various prion diseases according to the intervals from disease onset to sampling. (DOCX $20 \mathrm{~kb}$ )

Additional file 5: Figure S1. Description of $\mathrm{CH} 50$ values present within CSF from sampling until respective subject's death, derived from 31 sCJD cases. $X$-axis represents the interval time and $Y$-axis represents the $\mathrm{CH} 50$ values present within the CSF. P values among the groups are indicated above. (TIF $46 \mathrm{~kb}$ )

\section{Competing interests}

The authors declare that they have no conflict of interest.

\section{Authors' contributions}

CC designed the study, acquired the data and prepared the manuscript; YL acquired the data and prepared the manuscript; YL, XDY and JS performed ELISA; KX performed statistical analysis; WZ and QS prepared the CSF samples; $X P D$, who was the corresponding author, designed the study and prepared the manuscript. All authors read and approved the final manuscript.

\section{Acknowledgements}

This work was supported by Chinese National Natural Science Foundation Grants (81401670), China Mega-Project for Infectious Disease (2011ZX10004-101, 2012ZX10004215) and the SKLID Development Grant (2012SKLID102).

\section{Author details}

${ }^{1}$ State Key Laboratory for Infectious Disease Prevention and Control, National Institute for Viral Disease Control and Prevention, Chinese Center for Disease Control and Prevention, Chang-Bai Rd 155, Beijing 102206, China.

${ }^{2}$ Collaborative Innovation Center for Diagnosis and Treatment of Infectious Diseases, Zhejiang University, Hangzhou 310003, China. ${ }^{3}$ Chinese Academy of Sciences Key Laboratory of Pathogenic Microbiology and Immunology, Institute of Microbiology, Chinese Academy of Sciences, Beijing 100101, China.

Received: 12 August 2015 Accepted: 7 April 2016

Published online: 03 May 2016

\section{References}

1. Collinge J. Molecular neurology of prion disease. J Neurol Neurosurg Psychiatry. 2005;76(7):906-19.

2. WHO. WHO manual for surveillance of human transmissible spongiform encephalopathies including variant Creutzfeldt-Jakob disease. WHO Communicable Disease Surveillance and Response. 2003

3. Kovacs GG, Gasque P, Strobel T, Lindeck-Pozza E, Strohschneider M, Ironside JW, et al. Complement activation in human prion disease. Neurobiol Dis. 2004;15(1):21-8.

4. Daborg J, Andreasson U, Pekna M, Lautner R, Hanse E, Minthon L, et al. Cerebrospinal fluid levels of complement proteins C3, C4 and CR1 in Alzheimer's disease. J Neural Transm. 2012;119(7):789-97.

5. LV Y, Chen C, Zhang BY, Xiao K, Wang J, Chen LN, et al. Remarkable activation of the complement system and aberrant neuronal localization of 
the membrane attack complex in the brain tissues of scrapie-infected Rodents. Mol Neurobiol. 2015;52(3):1165-79.

6. Aeinehband S, Lindblom RP, Al Nimer F, Vijayaraghavan S, Sandholm K, Khademi $\mathrm{M}$, et al. Complement component c3 and butyrylcholinesterase activity are associated with neurodegeneration and clinical disability in multiple sclerosis. PLoS One. 2015;10(4):e0122048.

7. Ishii T, Haga S, Yagishita S, Tateishi J. The presence of complements in amyloid plaques of Creutzfeldt-Jakob disease and Gerstmann-StrausslerScheinker disease. Appl Pathol. 1984;2(6):370-9.

8. Klein MA, Kaeser PS, Schwarz P, Weyd H, Xenarios I, Zinkernagel RM, et al. Complement facilitates early prion pathogenesis. Nat Med. 2001;7(4):488-92.

9. Michel B, Ferguson A, Johnson T, Bender H, Meyerett-Reid C, Pulford B, et al. Genetic depletion of complement receptors CD21/35 prevents terminal prion disease in a mouse model of chronic wasting disease. J Immunol. 2012;189(9):4520-7.

10. Michel B, Ferguson A, Johnson T, Bender H, Meyerett-Reid C, Wyckoff AC, et al. Complement protein C3 exacerbates prion disease in a mouse model of chronic wasting disease. Int Immunol. 2013;25(12):697-702.

11. Tenner AJ, Fonseca MI. The double-edged flower: roles of complement protein C1q in neurodegenerative diseases. Adv Exp Med Biol. 2006;586:153-76.

12. Zabel MD, Heikenwalder M, Prinz M, Arrighi I, Schwarz P, Kranich J, et al. Stromal complement receptor CD21/35 facilitates lymphoid prion colonization and pathogenesis. J Immunol. 2007;179(9):6144-52.

13. Chen C, Xiao D, Zhou W, Shi Q, Zhang HF, Zhang J, et al. Global Protein Differential Expression Profiling of Cerebrospinal Fluid Samples Pooled from Chinese Sporadic CJD and non-CJD Patients. Mol Neurobiol. 2014:49(1):290-302.

14. Keller A, Nesvizhskii Al, Kolker E, Aebersold R. Empirical statistical model to estimate the accuracy of peptide identifications made by MS/MS and database search. Anal Chem. 2002;74(20):5383-92.

15. Toledo JB, Korff A, Shaw LM, Trojanowski JQ, Zhang J. Low levels of cerebrospinal fluid complement 3 and factor $\mathrm{H}$ predict faster cognitive decline in mild cognitive impairment. Alzheimer's research \& therapy. 2014;6(3):36.

16. Erlich P, Dumestre-Perard C, Ling WL, Lemaire-Vieille C, Schoehn G, Arlaud $\mathrm{GJ}$, et al. Complement protein $\mathrm{Clq}$ forms a complex with cytotoxic prion protein oligomers. J Biol Chem. 2010;285(25):19267-76.

17. Hasebe R, Raymond GJ, Horiuchi M, Caughey B. Reaction of complement factors varies with prion strains in vitro and in vivo. Virology. 2012;423(2):205-13.

18. Shi Q, Xie WL, Zhang B, Chen LN, Xu Y, Wang K, et al. Brain microglia were activated in sporadic CJD but almost unchanged in fatal familial insomnia and G114V genetic CJD. Virol J. 2013;10(1):216.

19. Shi Q, Chen LN, Zhang BY, Xiao K, Zhou W, Chen C, et al. Proteomics analyses for the global proteins in the brain tissues of different human prion diseases. Mol Cell Proteomics. 2015;14(4):854-69.

20. Boesenberg-Grosse C, Schulz-Schaeffer WJ, Bodemer M, Ciesielczyk B, Meissner B, Krasnianski A, et al. Brain-derived proteins in the CSF: do they correlate with brain pathology in CJD? BMC Neurol. 2006;6:35.

21. Ladogana A, Sanchez-Juan P, Mitrova E, Green A, Cuadrado-Corrales N, Sanchez-Valle $\mathrm{R}$, et al. Cerebrospinal fluid biomarkers in human genetic transmissible spongiform encephalopathies. J Neurol. 2009;256(10):1620-8.

22. Higuma M, Sanjo N, Satoh K, Shiga Y, Sakai K, Nozaki I, et al. Relationships between clinicopathological features and cerebrospinal fluid biomarkers in Japanese patients with genetic prion diseases. PLoS One. 2013;8(3):e60003.

23. Chen C, Zhou W, Lv Y, Shi Q, Wang J, Xiao K, et al. The Levels of Tau Isoforms Containing Exon-2 and Exon-10 Segments Increased in the Cerebrospinal Fluids of the Patients with Sporadic Creutzfeldt-Jakob Disease. Mol Neurobiol. doi:10.1007/s12035-015-9348-2.

24. Shiga Y, Wakabayashi H, Miyazawa K, Kido H, Itoyama Y. 14-3-3 protein levels and isoform patterns in the cerebrospinal fluid of Creutzfeldt-Jakob disease patients in the progressive and terminal stages. J Clin Neurosci. 2006;13(6):661-5.

\section{Submit your next manuscript to BioMed Central and we will help you at every step:}

- We accept pre-submission inquiries

- Our selector tool helps you to find the most relevant journal

- We provide round the clock customer support

- Convenient online submission

- Thorough peer review

- Inclusion in PubMed and all major indexing services

- Maximum visibility for your research

Submit your manuscript at www.biomedcentral.com/submit
Biomed Central 